\title{
A new set of performance indicators for improving the capitalization process of Intellectual Property
}

\author{
Alexandra HADĂR \\ University Politehnica of Bucharest, Bucharest, Romania \\ alexandrahadar@yahoo.com \\ Anca Alexandra PURCĂREA \\ University Politehnica of Bucharest, Bucharest, Romania
}

\begin{abstract}
Performance indicators of technology transfer/ knowledge activity, of intellectual property capitalization in a technical university as well as those referring to the monitoring of academic entrepreneurship are closely correlated, in terms of objectives and strategies adopted at European level, in the context of the third mission undertaken by universities of the XXI century. So far, a systematic research on the development about the capitalization process of intellectual propertytechnical universities in Romania was not conducted. In this context, the analysis and adoption of a new set of indicators for monitoring and evaluating institutional performance, appropriate to an optimization model applicable in academic environment, is required to support the growth of its competitiveness. The present analysis involved the achievement of a research in two stages, one quantitative and the other qualitative, defining, in a rational manner, the set of indicators for monitoring and evaluating the institutional performance. Analysis began with a quantitative research, where the number of indicators, originally envisaged, was limited. Following this research there were retained only the indicators having a weight of over 50\%. For a better formulation of the problem investigated and for some conceptual clarification it was achieved a qualitative research, conducted through a focus group, two authors scrolling two such research. Following qualitative research, carried out in order to classify indicators for monitoring and evaluation the performance analysis of technology transfer / knowledge within a public research organizations, i.e. a technical university, we decided the importance ranking of the first three indicators: a) the number of direct contracts with the socio - economic environment; b) the number of contracts and research projects financed through competitive mechanisms, in collaboration with partners from outside the academic environment and c) the revenue generated from the commercialization of knowledge from higher education institutions (revenue from licenses, income from royalties etc.).
\end{abstract}

Keywords: technology transfer/ knowledge activity, intellectual property capitalization, set of indicators, quantitative and qualitative research

\section{Introduction}

Modern universities are oriented to strengthening the connections between the academic and socio-economic environment and public authorities. A higher accent on the applicative research can be noticed worldwide and the research institutes and universities are those institutions that are the most suitable to answer to the demands of solving the needs of the society, to develop and modernize it.

The known pattern of intellectual property capitalization does not target all possible trajectories of knowledge generation nor the procedures of capitalization of the results of research in connection with the education component.

The performance indicators of the technologic / knowledge transfer activity of capitalization of intellectual property in a university and the indicators of monitoring the academic entrepreneurship are in a tight correlation from the perspective of the adopted 
objectives and strategy, in the context of the third mission assumed by the XXIst century universities.

In this respect, it is important to adopt and analyze a new set of indicators of monitoring and evaluation of the institutional performance, adequate for a model of optimization that can be applied in the university environment and which can support the increase of it's competitiveness.

PICBE | 995

The analysis is done through a two stage research, a quantitative one and a qualitative one (focus-group type) that define in a rational manner the set of indicators of monitoring and evaluation of the institutional performance.

\section{Literature review}

Together with education and research as classic missions of an university, a third mission appears: collaboration with the economic environment for the development of society.

Transition towards the accomplishment of this mission is known as "the second academic revolution" (Youtie et al., 2008). The universities that are involved in this process are oriented to the capitalization of intellectual property in the social and economic environment through activities of applicative scientific research materialized in new products, modern technologies and services of higher quality than those that exist in the present days.

There are studies that identify four important groups of factors that can contribute to the improvement of capitalization of the university intellectual property in the economic environment (Gomez-Gras et al., 2007):

-internal policy and strategies of the university - that can promote or inhibit the capitalization of the university intellectual property;

-stock of technology - that determines the occurrence of opportunities for capitalization;

-resources and initiatives directly structured to create support for capitalization;

-human capital regarding the number of potential entrepreneurs coming from the academic environment and their characteristics.

In this context, it is necessary that each university develops its own strategic plans that include clear objectives connected with the capitalization of intellectual property (Tran, 2013).

Present studies show very small number of systematic approaches regarding the development of the process of capitalization of intellectual property in technical universities from countries having a transition economy, like Romania (Sectorial Project, 10S/04.02.2015).

An important problem of the applicative research can be noticed, regardless of the field of application and it is connected to the indicators of improvement and optimization of the technologic transfer processes (Bozeman et al., 2015).

That is why in this study we aim to elaborate a new set of indicators for monitoring and evaluation of institutional performances from the perspective of knowledge transfer and capitalization of intellectual property, which can be applied in the university environment.

These indicators were grouped thematically and allowed us to realize a detailed analysis for the implementation of a rigorous control of the knowledge transfer processes. 


\section{Research methodology}

\section{Quantitative research (Study nr. 1)}

A quantitative research was undertaken using a questionnaire, having as the main goal to identify new indicators for monitoring and evaluation of the institutional performance and which can be adapted to an optimization model that can be applied in the university environment.

This questionnaire was sent to 55 people, all of them being faculty members from University Politehnica of Bucharest, Technical University of Civil Engineering Bucharest, "Sttefan cel Mare" University of Suceava, University of Craiova and Technical University "Gheorghe Asachi" from Iasi or researchers from research institutes and innovative small and medium enterprises.

The questionnaire had 18 indicators on which the subjects expressed their opinion regarding the degree of importance.

Following the analysis, the indicators with less than $50 \%$ percentage in the opinions are not relevant and were excluded from the subsequent qualitative research. A classification of the first eight indicators was done and the first eight are further presented. The order in which the indicators were mentioned in the questionnaire were kept in this work.

The importance of capitalization of intellectual property through the number of contracts and research - development - innovation projects in collaboration with partners outside the academic environment financed by the state through grant competitions is shown in Fig. 1.

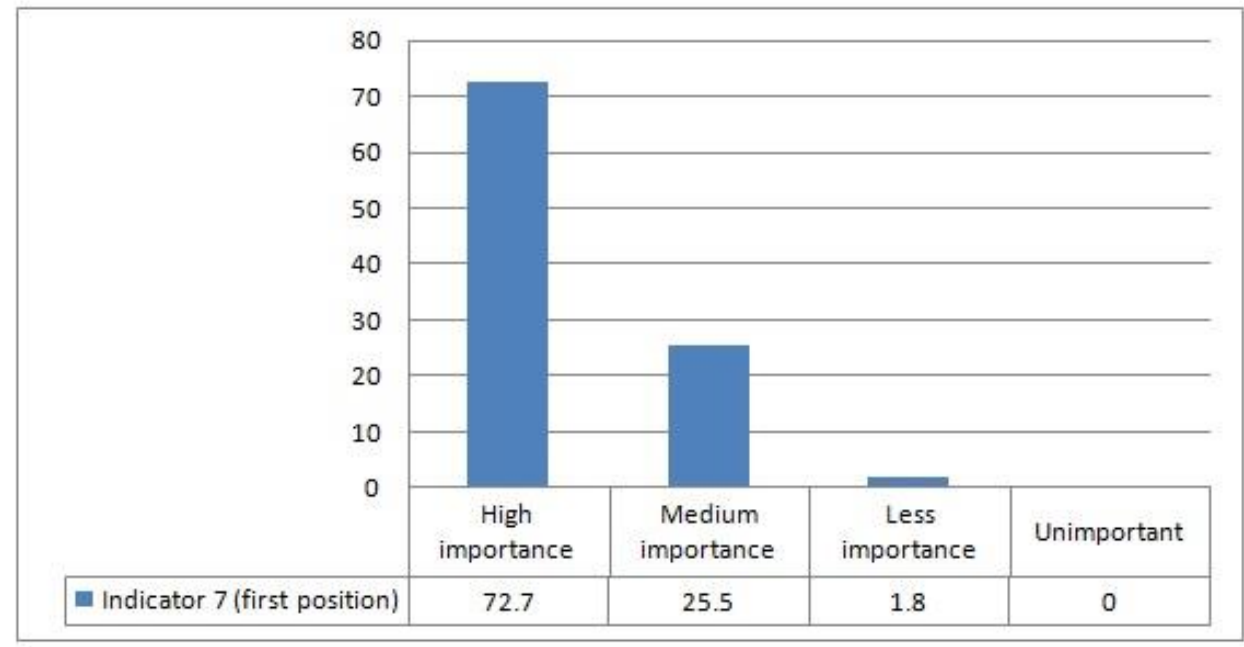

Figure 1. The importance of capitalization of intellectual property through the number of contracts and research - development - innovation projects in collaboration with partners outside the academic environment

Source: Authors' own research results.

The majority of responders have appreciated the fact that important problems of industrial companies can be solved through such contracts that need modern mechanisms of approach such as complex research studies, since the private companies lack human resources specialized on research and innovation problems. In turn, universities are 
interested in such contracts, in order to obtain supplementary income and to get closer to the economic environment (model of innovative-entrepreneurial university).

From discussions with responders, it was shown that the economic environment is more and more interested to improve the relationship with universities through:

- internships for students;

- capitalization of results of the student research activities;

PICBE | 997

- suggestions on the university curriculum;

- programs of training for students, especially for master studies on subjects in which companies are interested;

- licence and disertation themes with high degree of aplicability and subjects of interest for companies.

Some problems mentioned by the responders can be solved through contracts financed by private companies.

The importance of another indicator, namely the number of contracts directly with the socio-economic environment is presented in Fig. 2.

The increase of the number of contracts between universities and the economic environment should be a continuous target of each university. Such contracts can be developed based on research or patents created in the universities and offered to the economic environment by leasing or other forms.

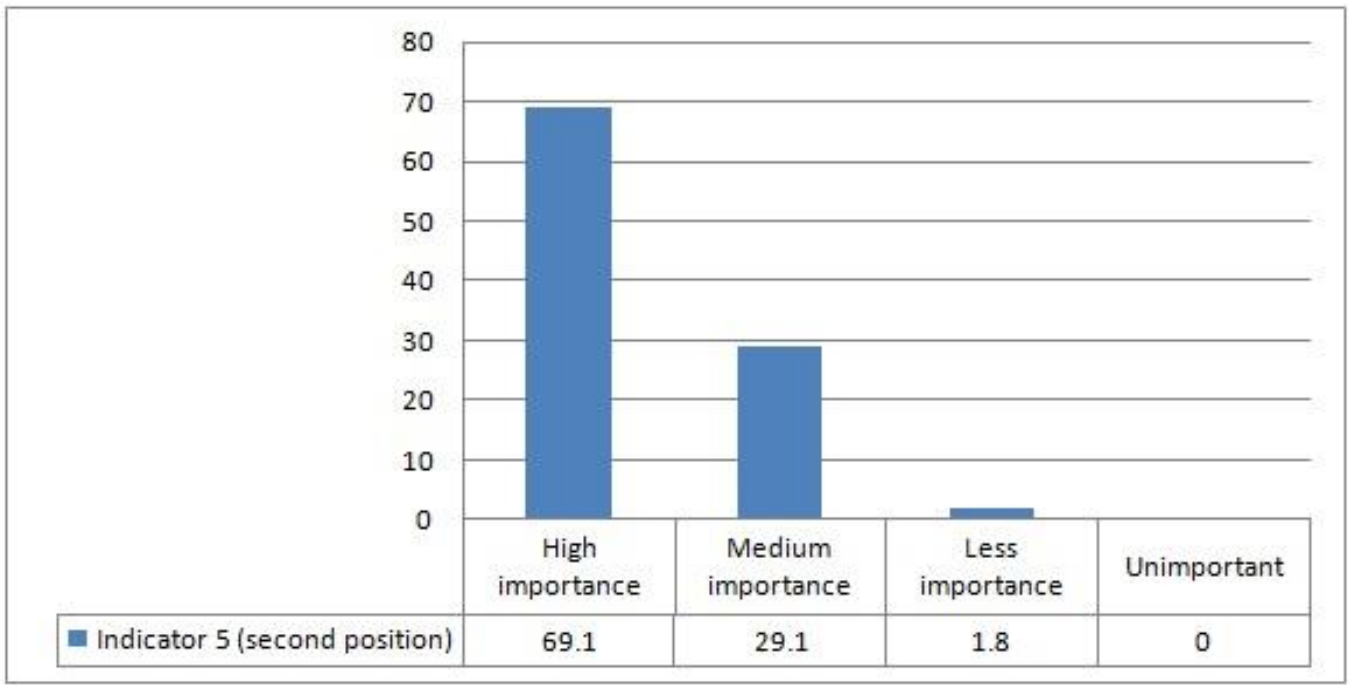

Figure 2. Importance of the number of direct contracts with the socio-economic environment

Source: Authors' own research results.

Nevertheless, the most efficient way of capitalization of the intelligence and creativity of the specialists in the universities is development of contracts on themes demanded by the economic environment in order to design products, technologies and services that are competitive on national and international level, ensuring also the development of companies.

In Fig. 3 is depicted the answer of the specialists on the indicator number of research - development - innovation laboratories / buildings / facilities created (co-financed) totally or realized partially in colaboration with partners outside the academic environment. 


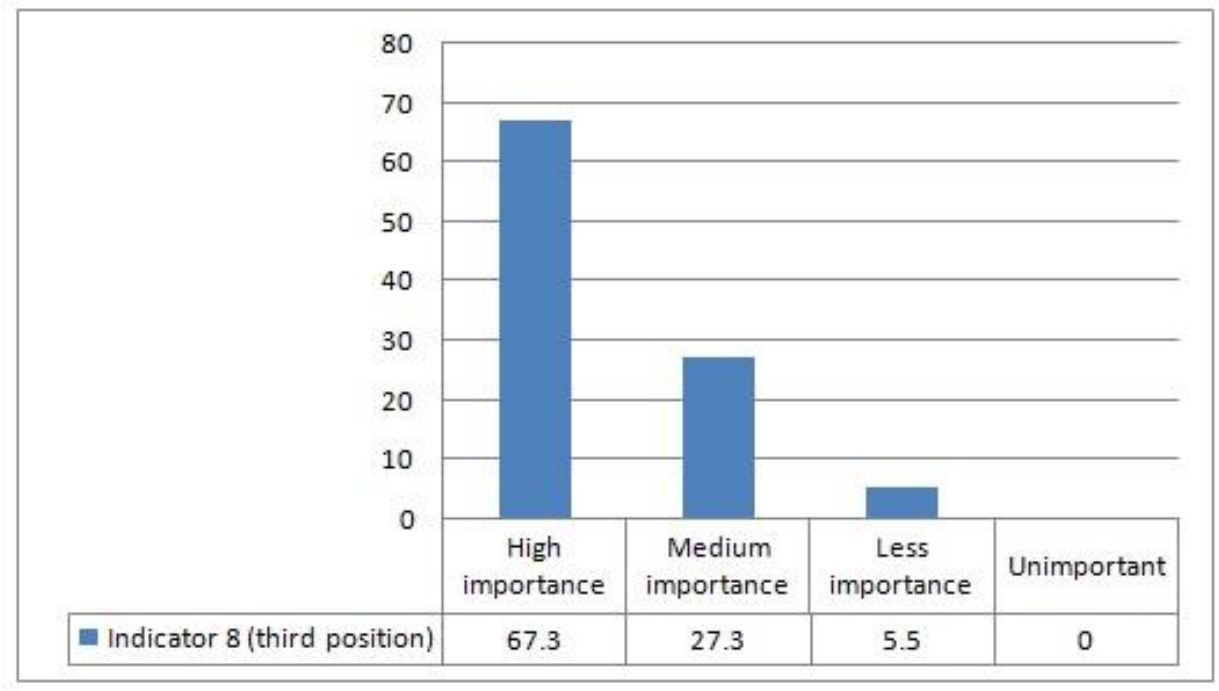

PICBE | 998

Figure 3. Results of the questionnaire regarding the indicator"number of research development - innovation laboratories / buildings / facilities created (co-financed) totally or realized partially in collaboration with partners outside the academic environment".

Source: Authors' own research results.

In the last years, the universities developed the research and education infrastructure especially through national or international research contracts funds. In the same time, in many universities, modern laboratories with state-of-the art equipment appeared following colaboration swith private companies. Such laboratories are used both in the educational process and in research activities.

On the other side, the private companies have the interest to create common research laboratories in which students are trained using modern technologies in order to increase the quality of higher education and to train the students close to the necessities and profile of the companies. Having modern equipments, researches undertaken in the universities in the laboratories created through partnerships with private companies may be closer to the wishes and demands of private investors.

Another indicator that was analyzed is the one shown in Fig. 4, namely the number of master students / post-doctoral researchers directly financed or co-financed from public or private funds on applicative research programs. 


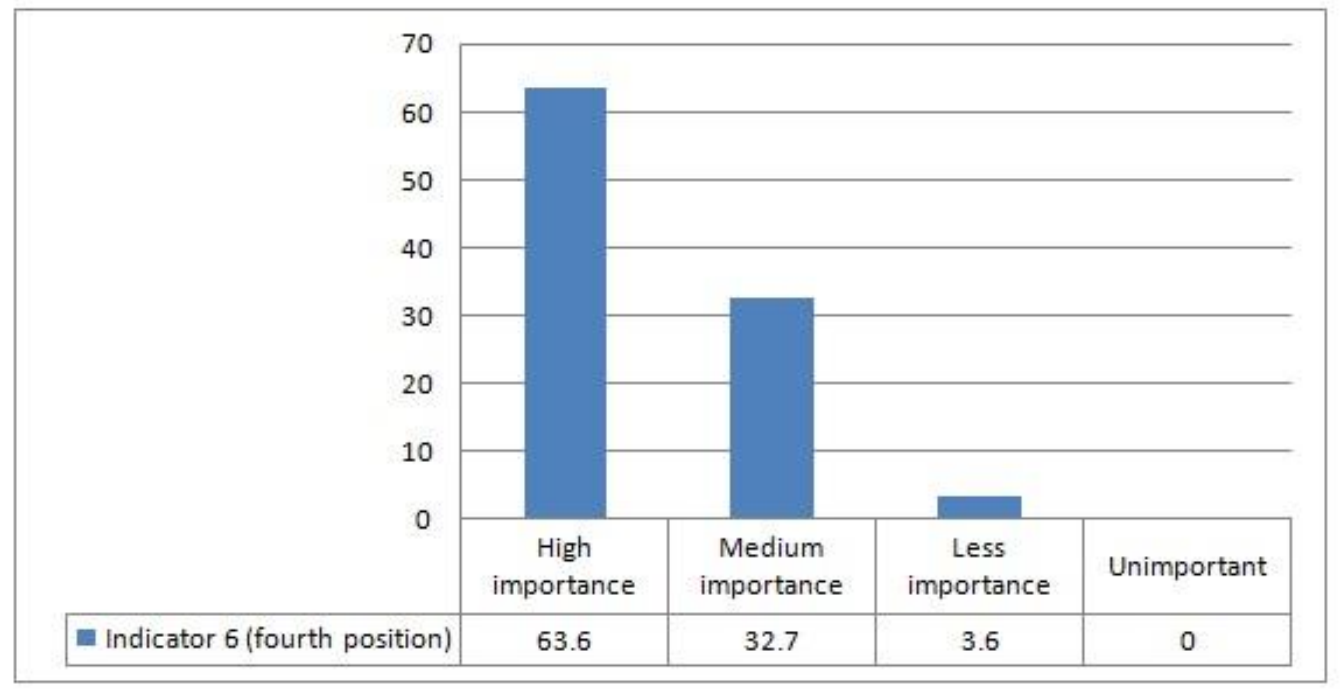

PICBE | 999

Figure 4. Results of the questionnaire regarding the indicator "number of master students /post-doctoral researchers directly financed or co-financed from public or private funds on applicative research programs"

Source: Authors' own research results.

The significance of this indicator is that, in order to obtain high quality results in the economic environment and to optimize the transfer of technology it is important that the graduates undertake post-university courses, doctoral and post-doctoral studies financed from different sources. The responders consider that the applicative research programs run at the demand and with the implication of the economic environment are extremely useful.

In the last years, doctoral and post-doctoral studies have been substantially financed using European funds. In this way, many generations of specialists were trained at top level.

Another significant element regarding the transfer of technology - the number of patents along the analyzed year - is shown in Fig. 5.

For sure, the number of patents in a certain university is an indicator of the efficiency and value of applicative research. To owe a patent does not necessarily mean to valorify it in the economic environment.

If services of technology transfer from a university would be developed and if the economic environment would strengthen the collaboration with universities, then for sure new products, technologies or services would arise from such collaboration.

On another side, if the universities would patent products or technologies of interest for private companies (in other words if the university research would be closely connected to problems of interest for the economic environment) then the knowledge technology transfer would increase visibly. 


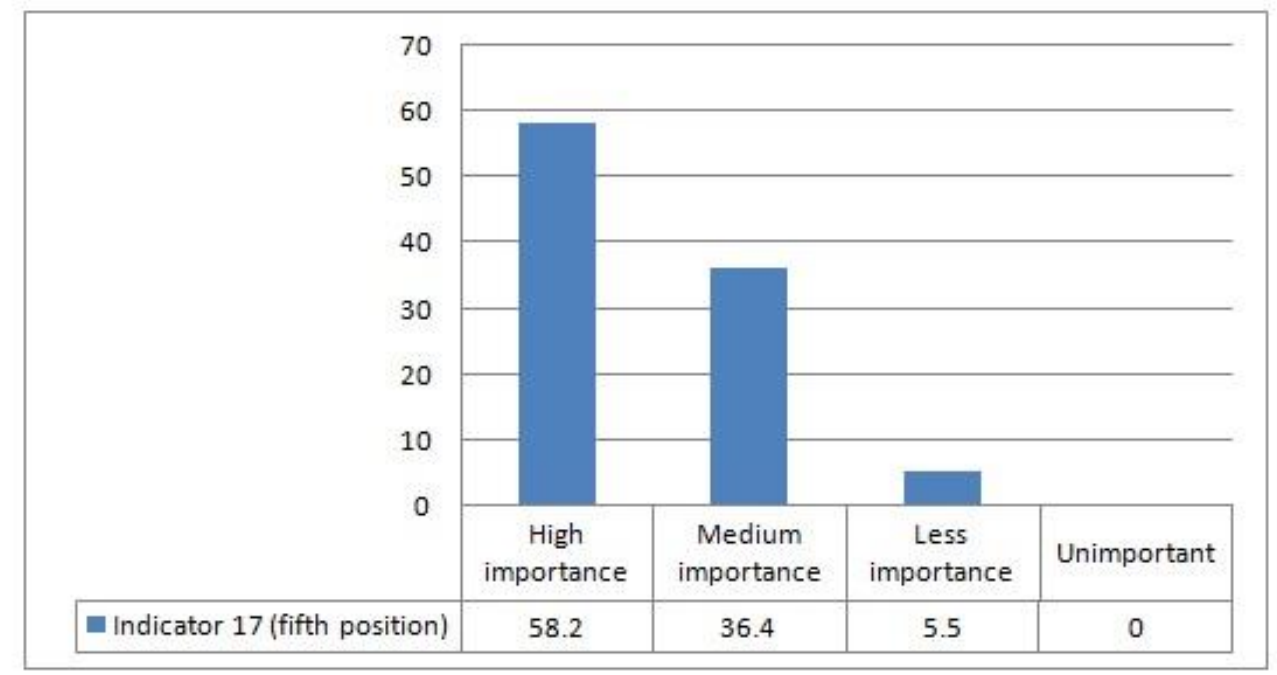

PICBE |

Figure 5. Relevance of capitalization of the intelectual property through patents

Source: Authors' own research results.

As it can be seen from Fig. 6, a modern mechanism for the exploitation of intellectual property in universities is the creation of start-up/ spin-off companies through which technology and innovation can reach the market. companies.

Unfortunately, there are few Romanian universities that have created such

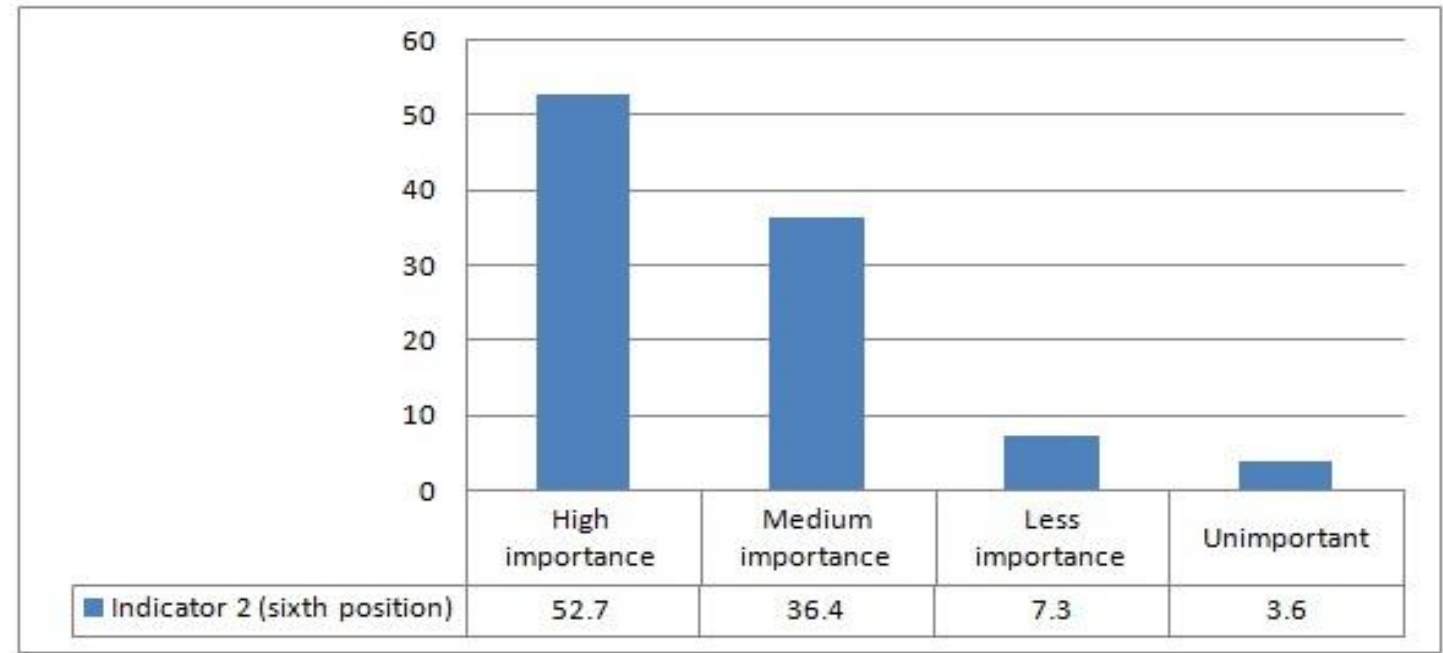

Figure 6. Importance of technology transfer by setting up start-up/ spin-off companies

Source: Authors' own research results.

As a result of the survey, more than half of the respondents considered this indicator to be of great importance: the increase of the income from licenses and copyright gained represents, for both the university and its employees, opportunities to obtain additional earnings, resulting from research - innovation activities. Therefore, universities must support the participation of inventors in showrooms, fairs and symposiums 
organized on innovation and technology transfer issues, with patents obtained on behalf of the university.

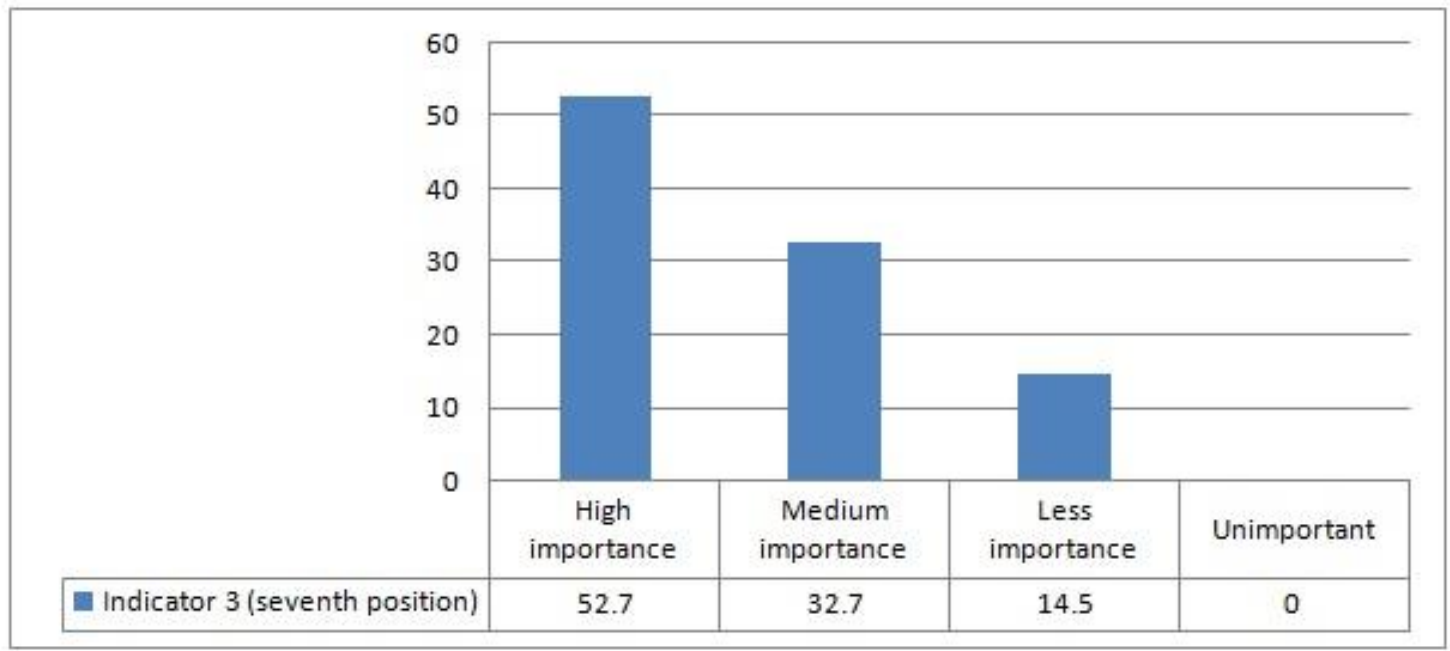

PICBE |

Figure 7. The graphical significance of the technology licensing indicator

Source: Authors' own research results.

According to the survey, respondents believe that universities need to develop stronger relationships with the economic environment, one of the ways being to conduct consultancy contracts through which professors and researchers can provide studies, analyzes, researches and innovative ideas to the market. In the last period there is an increase in the number of consultancy contracts in favor of the economic environment, coordinated by academic specialists, on various issues.

There is a visible increase in the confidence of the representatives of the economic and social environment in the academic body of universities, highlighted by a series of punctual problems that the economic environment solves together with the university.

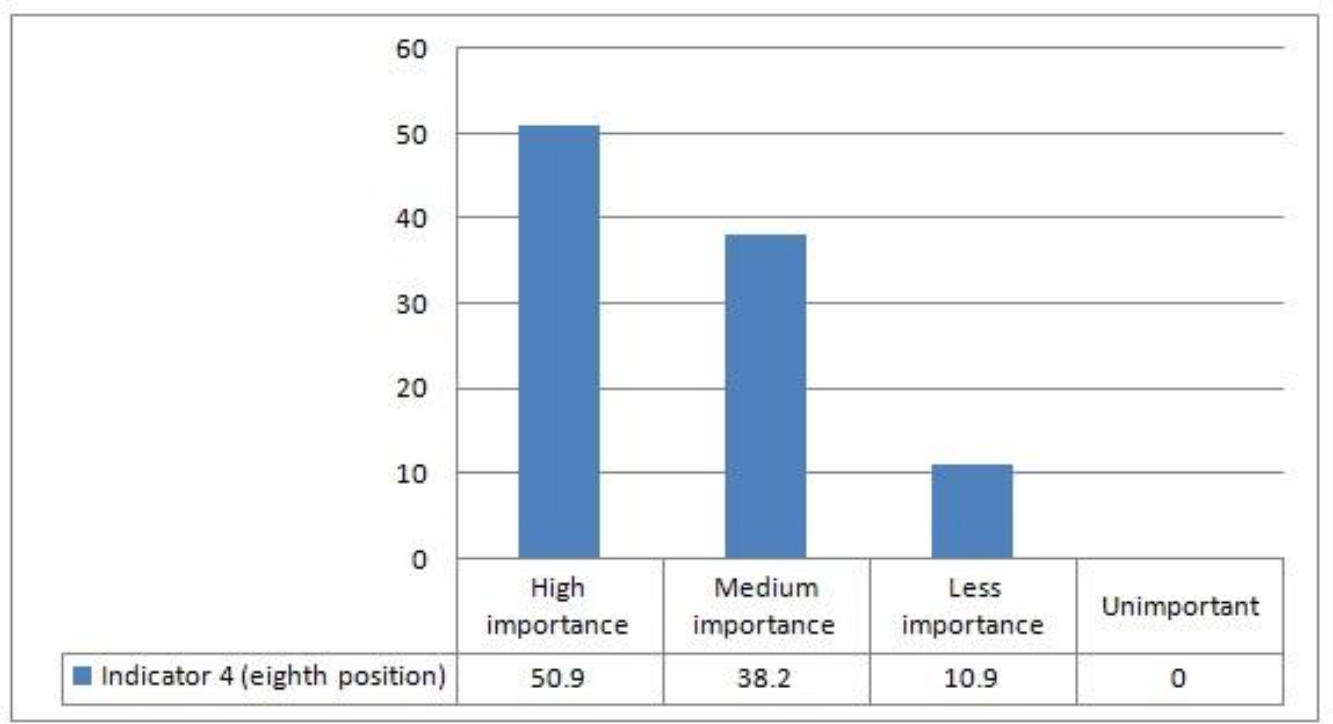

Figure 8. The graphical representation of the indicator "Number of consultancy contracts in favor of partners outside the economic environment"

Source: Authors' own research results. 


\section{Qualitative research through focus-group (Study nr. 2)}

In order to increase the degree of trust and understanding of the results obtained through the quantitative analysis and to justify the position of the studied indicators, and also in order to ensure the correctness of the research from the scientific point of view, the authors have undertaken also a qualitative analysis by organizing two focus-groups. Analysis of results obtained from qualitative research through the focus group was conducted by the classical method of comprehensive analysis, method ensuring a high degree of validity and reliability of the final results. There were obtained important information, from people with knowledge and experience in the field of technology transfer: employers (representatives of the economic environment), professors, researchers and $\mathrm{PhD}$ students.

In the following is presented how the qualitative research is being carried out, completing the analysis on the new set of indicators for monitoring and evaluating institutional performance.

The sampling of the persons involved in focus-groups in the interviews does not consider account statistical representativeness rules, but theoretical sampling rules, taking into account the general objectives of the research and the dominant characteristics assumed in the hypothetical model.

Debates have started with the presentation of the subject approached in the focusgroups, generated by the initiative of analyzing the institutional performance of a technical university from the perspective of technologic transfer, innovation and entrepreneurship through a new set of indicators of monitoring and evaluation of performance. Participants were asked to state and explain why they accepted the invitation to participate in this focus-group.

Several questions were addressed to the participants, some of them being presented below.

1. What is your opinion about innovation and knowledge transfer/ technology?

Through this first question, which has been on long debated, it has been identified how to understand the concept of "innovation".

Participants believe that innovation is the action to bring new products/ technologies/ services to the market in a specific domain.

A first aspect identified and approached by one of the participants referring to this question is the concept of open innovation, which involves the use of internal and external knowledge resources for the faster development of a technology that will expand even further on the market.

As a recommendation, a professor states that, through research should result applications and the performance be measured in the industrial environment, with the emphasis on concrete systems.

So, to sum up one can say that innovation includes new services, products and technologies, and even the upgrading of existing technologies. Through technology transfer are understood those activities that take a result from research, for example, a novelty or an invention, and are used by a potential beneficiary.

2. How do you think that the intellectual property of universities can be capitalized? Is this process related to the commercialization of innovative technology created and developed in academic environment or not? 
One of the participants considers the transition from prototype to serial production is an important step. Another participant mentioned that sometimes it happens that the prototype is incorrectly performed and malfunctions occur in serial production. It recommends the development of students creativity and their innovative spirit through diverse practical activities, modern laboratories etc.

Another professor states that the exploitation of intellectual property is realized PICBE | through the entrepreneurial mission, where student training and research are market 1003 oriented.

The development of the innovative spirit of students and professors should be a permanent objective for each university. Technical universities must become as soon as possible innovative and entrepreneurial universities.

Moreover, another important aspect is that the universities should organize master programs requested by the economic and social environment, funded by the budget and/ or by the applicants.

The scientific research of technical universities must follow the needs and demands of the labor market.

3. How should be made the connection between the academic and socio-economic environment regarded not only as companies but the whole society? How this partnership should be established from the perspective of the knowledge - technologic transfer? How this connection should be made?

The participants considered that, for a better collaboration with the economic environment, the student research should be made within the private companies, on subjects elaborated together with the specialists from these companies. One of the participants also mentions about partner search with the LinkedIn social network, creating an account, analyzing calls or contacting the first author of the article of interest. Also, the subjects of license and dissertation work and mainly of PhD work should be focused on the needs of companies, in order to make practical application of such work easier. Also, the participants underlined that the support of the government for the companies that collaborate with universities is necessary. An important element in the development of the collaboration between the universities and the socio-economic environment should be the participation of companies and universities in as many research - development innovation projects as possible.

4. What are the main problems to which an university is confronted and what are the aspects that should be improved or changed in the relationship university - business environment - society from the perspective of the ratio between the novelty in scientific research, inventions and innovation?

The participants considered that the problem of professional formation is very important for the society and especially for the companies. Universities can improve their relationship with the economic and social environment also through courses of professional formation for adults if:

- the confidence of the economic environment in the capacity of the universities to develop such courses increase;

- a process of common empowering both from universities and the business environment and society takes place regarding the efficiency of the courses, the degree of novelty, and, mainly, the openness of the university to the problems of the society; 
- universities answer to the request of the economic environment by organizing courses demanded by them (continuous formation or master) at the premises of the companies when possible;

- the curricula are elaborated together with the employers;

- financing exists from the economic environment.

Another aspect considered necessary to improve in university - economic PICBE | environment relationship would be that the approached themes be more oriented towards $\mathbf{1 0 0 4}$ the market and its needs.

Participants considered that the internationalization of lifelong learning services should be an objective of each university. Some successes of University POLITEHNICA of Bucharest have been highlighted in collaboration with national and international companies in fields such as: automation and computers, energy, electronics, industrial engineering, mechanical engineering etc., collaboration for the commissioning of modern facilities and training professional specialists in the economic environment.

The social role of universities could increase through attractive job offers for vocational training and reconversion of unemployed people and through the improvement of engineering teachers from pre-university education.

5. What is the relationship between the facilities (for example high performance research equipment), professional competence of the personnel implied in innovative activities and the success in the activity of knowledge / technologic transfer?

It was a consensus on the very good quality of human resources and material resources in University POLITEHNICA of Bucharest. The participants also drew attention to other issues that can ensure the success of the technology transfer business. They again referred to the necessity of a marketing department in University POLITEHNICA of Bucharest, a solid one, without which efficient cooperation relations with the economic environment can not be developed, no matter how prepared the academic staff, the researchers and the students of the university, and no matter how good it is infrastructure with its equipment.

It is obvious that a valuable infrastructure together with competent and innovative human resources in a university are important factors regarding the knowledge and technology transfer towards the economic environment. The participants considered that it is also very important that the universities have specialists in marketing and communication. No matter how valuable an engineer is, he / she cannot be in the same measure a creator and a person that capitalizes his/her own ideas.

6. How can the students (master students, Ph.D. students, postdoctoral students) be attracted to innovative activities, especially in terms of knowledge transfer/ technology transfer?

The participants interventions throughout the focus-groups shown that students, dismissive of their study cycle, could be attracted to innovative activities if:

- are financially supported in their initiatives to create firms, patent their inventions, start-ups etc ;

- more emphasis will be focused on the practical aspects of the field of study they follow, a practice of all courses being considered necessary and beneficial for the development of students creativity and for their better entrepreneurial culture;

- are attracted to the research centers created by the economic environment in universities, especially master students and doctoral students. 
7. What would be three performance indicators taken into account by a company to judge the performance of a university in the field of the rapport knowledge transfer technology transfer?

First of all, it was mentioned the necessity to align the organizational culture of University POLITEHNICA of Bucharest with current socio-economic and technological paradigms, in order to create a space of understanding and knowledge between universities and companies.

PICBE

Several performance indicators have been proposed, the most often mentioned being:

- the number of collaborations between the university and the economic and social environment, materialized in: contracts, research projects, common patents, scientific articles in databases with joint authors, various partnerships and events developed together;

- the degree of receptiveness of enterprises for proposals of collaboration with universities;

- number of students in the field of engineering/ total graduates;

- market orientation of university research;

- the potential value of research results, the ability of that technology or that solution or result of research to generate profit in the economy.

After analyzing the content of the participants contributions to the focus group, it resulted that three of the relevant indicators in the quantitative research can be excluded from the new set of indicators for monitoring and evaluating the institutional performance, so the indicators that are no longer found in qualitative research are:

- Indicator 6: number of master students /post-doctoral researchers directly financed or co-financed from public or private funds on applicative research programs (fourth position, quantitative research);

- Indicator 4: Number of consultancy contracts in favor of partners outside the economic environment (eighth position, quantitative research);

- Indicator 2: Number of start-up / spin-off start-ups (sixth position, quantitative research).

This is the most important question necessary for the establishment of a new set of performance indicators of a technical university regarding the technology transfer to the economic environment. Following the qualitative research presented in this paper, the next ranking has resulted about the indicators of monitoring and evaluation of performances of the technology / knowledge transfer activity in a public research - development innovation organization:

1. Number of direct contracts with the socio-economic environment, privately financed;

2. Number of research - development - innovation contracts and projects financed from public funds, in collaboration with partners outside the academic environment;

3. Incomes from selling knowledge in high education institutions (licensing, royalties, etc.);

4. Number of patents obtained within the analyzed year;

5. Number of research - development - innovation laboratories / buildings / facilities created (co-financed) totally or realized partially in collaboration with partners outside the academic environment. 
It has been proposed to set up a marketing department in University POLITEHNICA of Bucharest, specializing in generating and capitalizing on research activities of the university, to which various other services can be assigned, such as: technology transfer, intellectual property, research and technological transfer funding, spin- offs etc.

\section{Results and discussion}

Following the quantitative analysis of the results regarding the indicators specific to the processes of "technology and innovation transfer"and of "technology stock", shown in Fig. 9 , one can notice that the majority of responders considered that the indicator with the highest importance is "number of research - development - innovation contracts in collaboration with partners outside the academic environment". This figure contains all the 18 indicators, the one presented above being on the first eight positions. The next three positions belong to:

- number of start-up / spin-off companies established;

- revenue generated from selling knowledge from high education institutions (revenue from licenses, royalties, etc.);

- number of consultancy contracts with partners outside the academic environment.

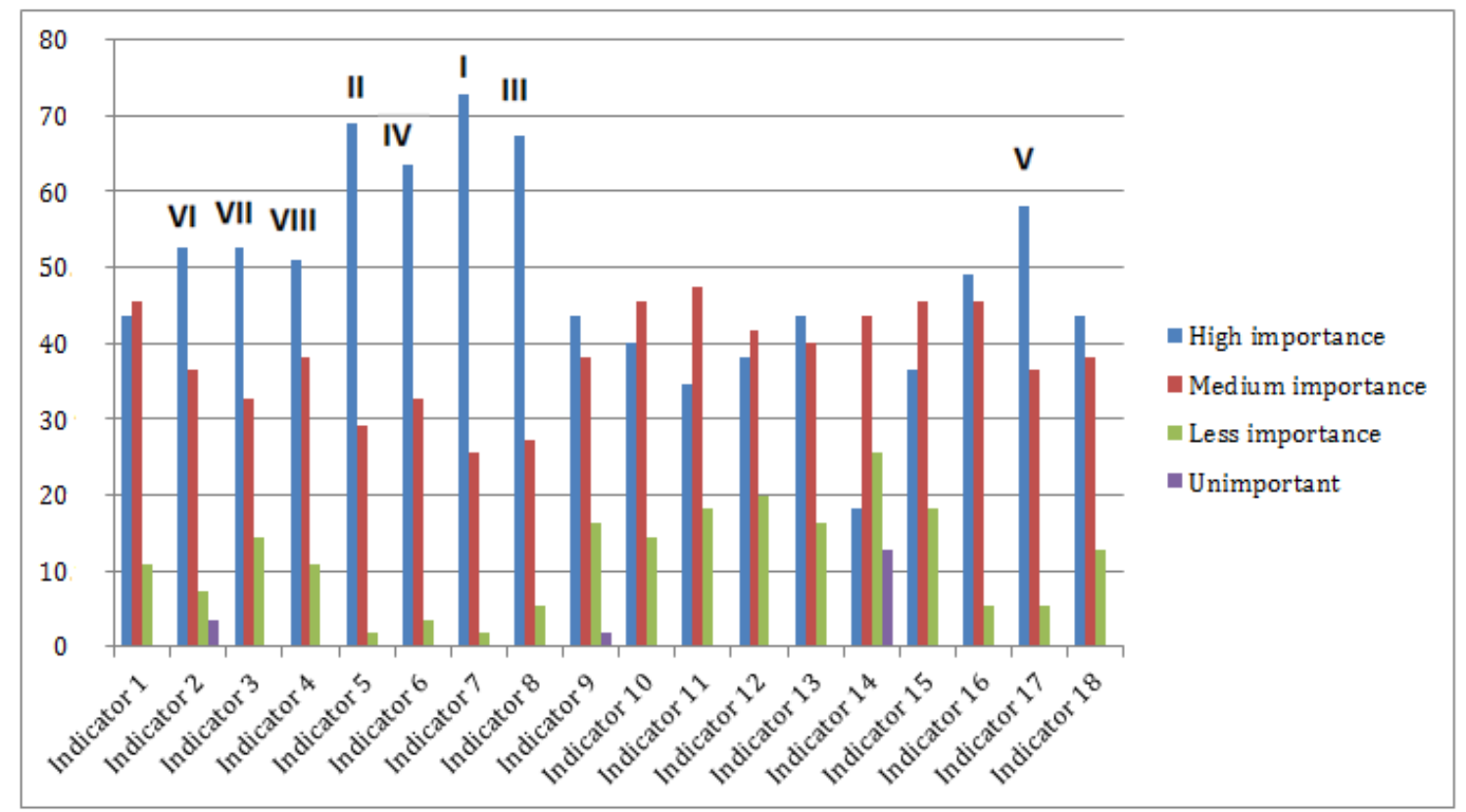

Figure 9. The first eight indicators specific to the processes of "technologic and innovation transfer" and of "technology stock"

Source: Authors' own research results.

One can notice that the first two indicators from the qualitative research (Study nr. 2) coincide with the first two positions from the quantitative research (Study nr. 1), but the order is different. A comparative analysis of the results from the two studies is presented in Table 1.

Table1. Comparison between the qualitative and quantitative studies

\begin{tabular}{|c|l|l|l|}
\hline Nr. & Study nr. & Indicator & Position \\
\hline 1. & Study 1 & Indicator 7 & $\begin{array}{l}\text { 1.Number of research - development - innovation contracts } \\
\text { and projects financed from public funds, in collaboration with } \\
\text { partners outside the academic environment }\end{array}$ \\
\hline
\end{tabular}

DOI: 10.1515/picbe-2017-0104, pp. 994-1008, ISSN 2558-9652| Proceedings of the $11^{\text {th }}$ International Conference on Business Excellence 


\begin{tabular}{|c|c|c|c|}
\hline & Study 2 & Indicator 5 & $\begin{array}{l}\text { 1.Number of direct contracts with the socio-economic } \\
\text { environment, privately financed }\end{array}$ \\
\hline \multirow[t]{2}{*}{2.} & Study1 & Indicator 5 & $\begin{array}{l}\text { 2.Number of direct contracts with the socio-economic } \\
\text { environment, privately financed }\end{array}$ \\
\hline & Study 2 & Indicator 7 & $\begin{array}{l}\text { 2.Number of research - development - innovation } \\
\text { contracts and projects financed from public funds, in } \\
\text { collaboration with partners outside the academic } \\
\text { environment }\end{array}$ \\
\hline \multirow[t]{2}{*}{3.} & Study 1 & Indicator 8 & $\begin{array}{l}\text { 3.Number of research }- \text { development }- \text { innovation } \\
\text { laboratories / buildings / facilities created (co-financed) } \\
\text { totally or realized partially in collaboration with partners } \\
\text { outside the academic environment }\end{array}$ \\
\hline & Study 2 & Indicator 3 & $\begin{array}{l}\text { 3. Revenues from selling knowledge in high education } \\
\text { institutions (licensing, royalties, etc.) }\end{array}$ \\
\hline \multirow[t]{2}{*}{4.} & Study 1 & Indicator 6 & $\begin{array}{l}\text { 4.Number of consultancy contracts in favor of partners } \\
\text { outside the academic environment }\end{array}$ \\
\hline & Study2 & Indicator 17 & 4.Number of patents obtained within the analyzed year \\
\hline \multirow[t]{2}{*}{5.} & Study 1 & Indicator 17 & 5.Number of patents obtained within the analyzed year \\
\hline & Study 2 & Indicator 8 & $\begin{array}{l}\text { 5.Number of research }- \text { development }- \text { innovation } \\
\text { laboratories / buildings / facilities created (co-financed) } \\
\text { totally or realized partially in collaboration with } \\
\text { partners outside the academic environment }\end{array}$ \\
\hline
\end{tabular}

PICBE |

From Table 1, a good convergence between the results of the quantitative and the qualitative research can be noticed, if several correspondences between the names of the indicators from the two studies are made.

The authors found that the first two indicators related to qualitative research, coincide with the first two positions in quantitative research.

\section{Conclusions}

The quantitative and qualitative research allow to define a synthetic indicator to couple the number of research - development - innovation contracts and projects financed from public funds, in collaboration with partners outside the academic environment with the number of direct contracts with the socio-economic environment, privately financed in a single indicator: Number of research - development - innovation contracts and projects developed in partnership with the socio-economic environment.

The number of research - development - innovation laboratories / buildings / facilities created (co-financed) totally or realized partially in collaboration with partners outside the academic environment should be connected to the integration of universities in scientific / technological parks and in research alliances as innovative clusters and competitiveness poles in the frame of the broad concept of professional networking.

The revenues generated by selling knowledge in high education institutions (licensing, royalties, etc.) should be correlated to licensing of technologies and development of new business (spin-off and start-up companies) started from the academic environment, despite the lack of confidence of the members of the academic community regarding the feasibility of such demarches.

The number of patents obtained by people from the academic environment should increase as a result of the educative and continuous professional formation demarches in the field of entrepreneurship for the benefit of students and representatives of the academic community. 
In such conditions, one can consider that the new indicators can be successfully applied in order to significantly improve the collaboration between the universities and the economic environment and in order to increase the performance of the knowledge transfer and capitalization of the intellectual property from the academic environment towards the society.

\section{References}

Youtie, J., Shapira, P.(2008).Building an innovation hub: A case study of the transformation of university roles in regional technological and economic development, Research Policy, 37(8), 1188-1204.

Gómez-Gras, J.M. (2007). Indicators of academic entrepreneurship: Monitoring determinants, start-up activity and wealth creation, Universidad Miguel Hernández de Elche.

Tran, T.A. (2013). Strategic Evaluation of University Knowledge and Technology Transfer Effectiveness, Dissertations and Theses, Portland State University.

Bozeman, B., Rimes, H., Youtie, J. (2015).The evolving state-of-the-art in technology transfer research: Revisiting the contingent effectiveness model, Research Policy, 44(1), 3449.

Dezvoltarea capacității de transfer și comercializare a rezultatelor din cercetare în cadrul institutelor și centrelor de cercetare aplicativă din România - implementarea unui model pilot pentru compartimentele de specialitate, Contract de tip Proiect Sectorial, 10S/04.02.2015 (in Romanian). 